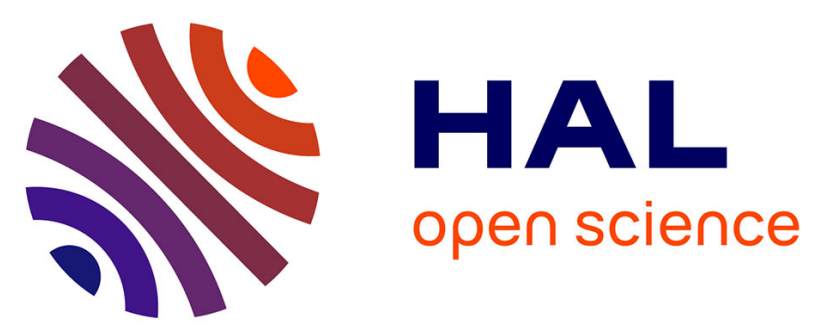

\title{
A NEW TECHNIQUE FOR SUBMONOLAYER NEXAFS : FLUORESCENCE YIELD AT THE CARBON K EDGE
}

D. N. Arvanitis, U. Dobler, L. Wenzel, K. Baberschke, J. Stöhr

\section{- To cite this version:}

D. N. Arvanitis, U. Dobler, L. Wenzel, K. Baberschke, J. Stöhr. A NEW TECHNIQUE FOR SUBMONOLAYER NEXAFS: FLUORESCENCE YIELD AT THE CARBON K EDGE. Journal de Physique Colloques, 1986, 47 (C8), pp.C8-173-C8-178. 10.1051/jphyscol:1986832 . jpa-00226154

HAL Id: jpa-00226154

https://hal.science/jpa-00226154

Submitted on 1 Jan 1986

HAL is a multi-disciplinary open access archive for the deposit and dissemination of scientific research documents, whether they are published or not. The documents may come from teaching and research institutions in France or abroad, or from public or private research centers.
L'archive ouverte pluridisciplinaire HAL, est destinée au dépôt et à la diffusion de documents scientifiques de niveau recherche, publiés ou non, émanant des établissements d'enseignement et de recherche français ou étrangers, des laboratoires publics ou privés. 


\title{
A NEW TECHNIQUE FOR SUBMONOLAYER NEXAFS : FLUORESCENCE YIELD AT THE CARBON $K$ EDGE
}

\author{
D. ARVANITIS, U. DOBLER* , L. WENZEL, K. BABERSCHKE and \\ J. STÖHR* *
}

Institut für Atom und Festkörperphysik, Freie Universităt Berlin, Arnimallee 14, D-1000 Berlin 33, F.R.G.

"Siemens Systemtechnik, Nonnendammallee 101, D-1000 Berlin 13, F.R.G.

** IBM, Almaden Research Center, San Jose, CA 95120-6099,

U.S.A.

Resumé: La structure fine au voisinage du seuil d'absorption X (NEXAFS) $\mathrm{K}$ du cärbone est mesurée pour de molecules d'hydrocarbures linéaires sur du $\mathrm{Cu}(100)$ à $60 \mathrm{~K}$. Nuatre modes possibles de detection sont comparés: Yield en fluorescence (FY), yield electronique en mode Auger (AEY), partiel (PEY) et total (TEY) sous les memês conditions experimentales. On prouve que la fluorescence est la technique la plus fiable, à cause du rapport accru sional sur fond $J_{R}: T_{R}(F Y)=10$, $\mathrm{J}_{\mathrm{R}}(\mathrm{AEY})=0,6, \mathrm{I}_{\mathrm{R}}(\mathrm{PEY})=0,17$ et $\mathrm{J}_{\mathrm{R}}(\mathrm{TEY})=0,05$. Des spectres en sous-monocouche de $\mathrm{C}_{2} \mathrm{H}_{2}, \mathrm{C}_{2} \mathrm{H}_{4}, \mathrm{C}_{2} \mathrm{H}_{6}$ sur du $\mathrm{Cu}(100)$ sont présentés.

Abstract: Near Edge X-ray Absorption Fine Structure (NEXAFS) measurements at the $\mathrm{C} K$ edge are used to investidate linear hydrocarbon molecules on $\mathrm{Cu}(100)$ at $60 \mathrm{~K}$. Four different detection modes are compared under the same experimental conditions: fluorescence yield. (FY), Auger electron yield, (AEY), partial electron yield (PEY) and total electron Yield (TEY). Because of an increase of the edge jump ratio $J_{R}$ due to reduction in background intensity the fluorescence yield method is shown to be the most reliable. The values obtained for $J_{R}$ are: $J_{R}(F Y)=$ 10, $J_{R}(A E Y)=0,6, J_{R}(P E Y)=0,17$ and $J_{R}(T E Y)=0,05$. Submonolayer spectra of $\mathrm{C}_{2} \mathrm{H}_{2}, \mathrm{C}_{2} \mathrm{H}_{4}, \mathrm{C}_{2} \mathrm{H}_{6}$ on $\mathrm{Cu}(100)$ are presented.

\section{Introduction}

The Near Edae X-ray Absorption Fine Structure (NEXAFS) of a molecule contains useful information about the orientation with respect to the substrate and intra-molecular bond lengths $/ 1 /$. Many studies that measure the electron yield associated to the Auger deexcitation of the created $1 \mathrm{~s}$ core hole have been carried out in the past for monolayer coverages on metal surfaces $/ 1,2 /$ above the oxygen and nitrogen $\mathrm{K}$ edges. For many chemical studies, the carbon $K$ edge is the most important one. But around the carbon $k$ edoe, the strongly energy dependent transmission function of all monochromators, caused by contamination of the optical elements, limits the surface sensitivity which can be reached by means of the electron yield technigues.

A standard fioure of merit for any detection scheme at an adsorbate edge is the edge jump ratio $J_{R}$, which is defined as the count rate difference above and below the edge, normalized to the pre-edge back- 
ground /3/. A typical value of $J_{R}$ for one layer of hydrocarbons (such as $\mathrm{C}_{2} \mathrm{H}_{4}$ ) on a metal surface is on the order of only $1 \frac{0}{6}$ for the partial electron yield mode /4/. It is therefore worthwhile to develop alternative detection schemes that offer a larger $J_{R}$ and an ultimately higher surface sensitivity.

Recently, fluorescence yield detection at the $C K$ edge $/ 5 /$, has demonstrated the advantace of a larger $\mathrm{J}_{R}$, compared to electron detection. Here we illustrate the actual status of this technique through measurements on lineax hydrocarbons on submonolayer coverages on a $\mathrm{Cu}(100)$ surface at $60 \mathrm{~K}$. These experiments illustrate the possibilities of the technique at the $\mathrm{C} \mathrm{K}$ edoe, which is important because of the importance of carbon in surface physics and chemistry.

This technique opens new fields of investigation, due to the big escape depth of photons (figure 1), as interlayer studies, measures at higher pressures under reaction conditions. It is also suitable for the study of insulatino materials, as it is not directly sensitive to charging effects.

\section{Experimental}

The experiments were performed at the storage ring BESSY in Berlin, using the $5 \mathrm{X}-700$ plane grating monochromator. The flux around the $\mathrm{C} \mathrm{K}$ edọe was about $2 \cdot 10^{10}$ photons/sec (400 m A current), with an energy resolution of $1 \mathrm{eV}$. The sample was cleaned by $\mathrm{Ar}^{+}$bombardement, annealed to $300^{\circ} \mathrm{C}$ and checked using JEED and Aucer spectroscopies. spectra were recorded on the Aucer, partial, total electron yield modes as before $/ 6 /$, as well as the fluorescence yield mode. The experimental details of the UHV compatible proportional counter are given elsewhere $/ 5 /$. The solid angle was $5 \%$ of $4 \pi$ sr with an energy resolu-tion of $280 \mathrm{eV}$ FWHM at the $\mathrm{C} \mathrm{K}_{\alpha}$ line $(277 \mathrm{eV})$. By using a multichannel analyser, a window was set around the $C \mathrm{~K}_{\alpha}$ peak to limit the effects of electronic noise on the low eneray side and the possibly second order excited $\mathrm{Cu} I$ edges at the high energy side $/ 5 /$. In an electron yield experiment, the possibly higher harmonics excited channels would ơive a background contribution and. further decrease $J_{P}$.

All detectors were positioned at grazing angles with respect to the sample surface (figure $1, \beta=0^{\circ}$ ). The specularly reflected $x$-ray beam from the sample and the fluorescence detector are at normal angles to each other at normal $x$-ray incidence (figure $1, \alpha=0^{\circ}$ ). In that geometry the background due to the substrate is reduced and $J_{R}$ is maximized.

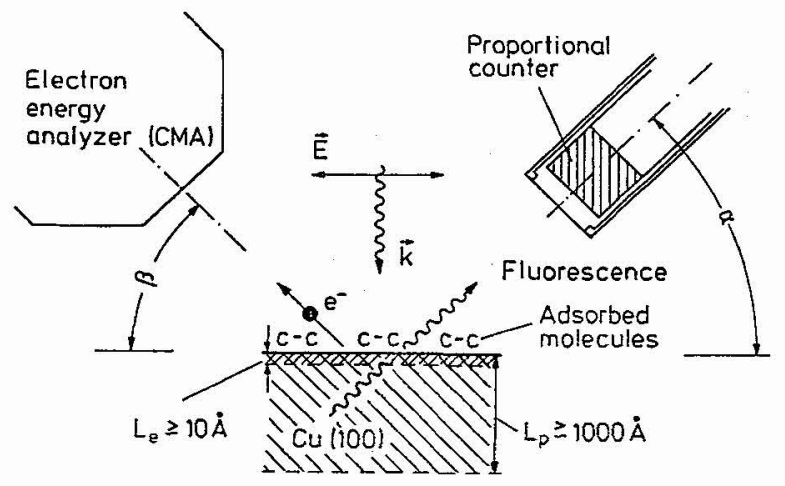

Fig. 1: Fluorescent photons and Auger electrons are created by filling a deep core hole created by a photon. The escape depth of the photons

$\left(L_{p}>1000\right.$ \&) is much laraer than the one of the electrons ( $\left.I_{e}>10 \AA\right)$. We have chosen $\xi^{\downarrow}=0^{\circ}$ and $\alpha=0^{\circ}$ Eor normal X'*ray incidence. 


\begin{tabular}{|c|c|c|}
\hline & $\begin{array}{l}c(2 \times 2) \\
S / N i(100\end{array}$ & $\begin{array}{l}10 \mathrm{I} \mathrm{C}_{2} \mathrm{H}_{4} \\
\text { on } \mathrm{Cu}(100)\end{array}$ \\
\hline Photon flux (ph/sec) & $2 \cdot 10^{10}$ & $\lambda 1 \cdot 10^{10}$ \\
\hline Atoms $/ \mathrm{cm}^{2}$ & $8 \cdot 10^{14}$ & $\lesssim 3 \cdot 10^{15}$ * \\
\hline K edge cross-section $\left(\mathrm{cm}^{2} / a t o m\right) * *$ & $6 \cdot 10^{-20}$ & $8,4 \cdot 10^{-19}$ \\
\hline $\mathrm{K}$ edge fluoresc. yield ** & $8 \cdot 10^{-2}$ & $1,5 \cdot 10^{-3}$ \\
\hline Solid angle fraction & 0,1 & 0,05 \\
\hline Window transmission & 0,4 & 0,25 \\
\hline Detector efficiency & $\approx 1$ & $\approx 1$ \\
\hline Estimated counts/s & 3070 & 470 \\
\hline Measured counts/s & 3000 & 400 \\
\hline
\end{tabular}

*Estimated using TDS spectroscopy

**CRC Handbook of Spectroscopy, Vol. 1, J.W. Robinson Edt. 1974

Table 1: Estimated and measured fluorescent yield count rates at the $\mathrm{S} / 3 /$ and $\mathrm{C} K$ edges. A small count rate is expected in our case due to the small fluorescence deexcitation probability with respect to the Auger process $\left(\sim 10^{-3}\right)$. The experimental conditions are comparable. Here the sample is looking to the detector $\left(\alpha=70^{\circ}\right)$ at grazing $x$-ray incidence. The count rate is decreased at normal $\mathrm{x}$-ray incidence with $\alpha=0^{\circ}$ (see text).

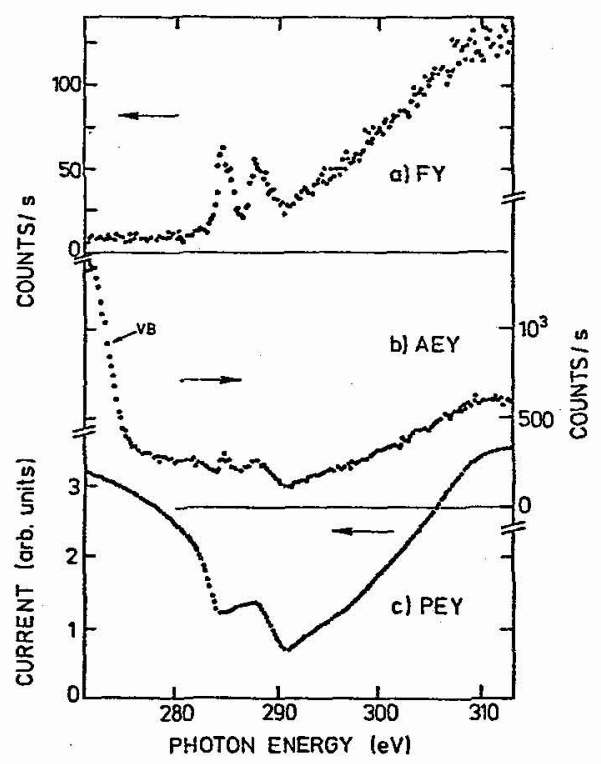

Fig. 2: Raw, unnormalized, spectra of fluorescence (a), Auger (b) and partial electron (c), yields, of $10 \mathrm{~L}_{2} \mathrm{C}_{4}(\sim 2 \mathrm{ML})$, at normal $\mathrm{X}-\mathrm{xay}$ incidence on $\mathrm{Cu}(100)$ at $60 \mathrm{k}$. 


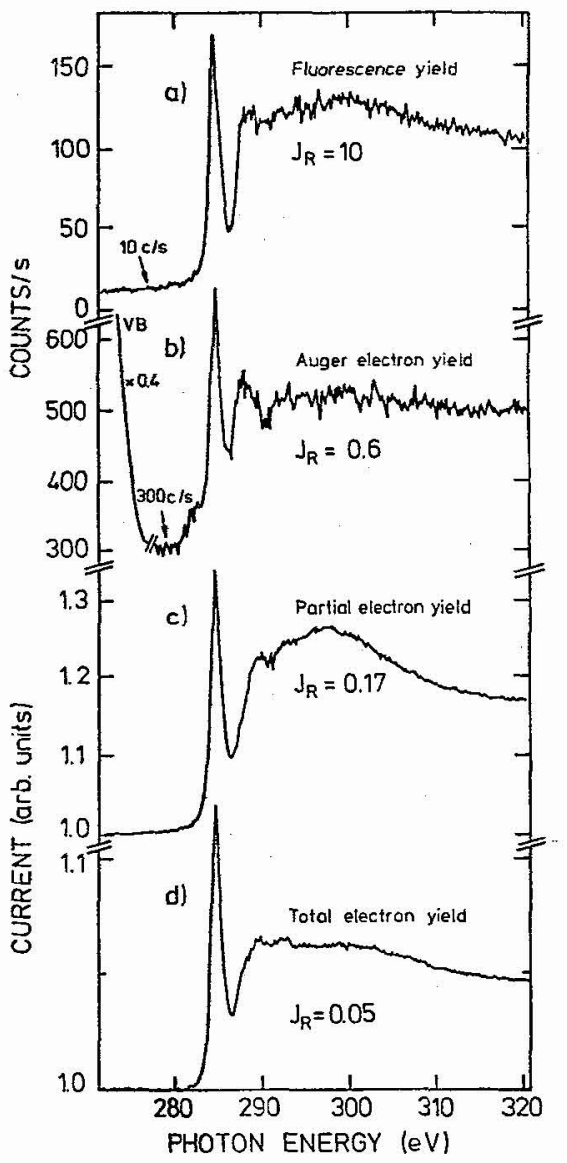

Fig. 3: Comparison of fluorescence yield with the three electron yield detection modes $/ 5 /$.

$a, b, c)$ Normal $x$-ray incidence.

d) $20^{\circ}$ Grazing $x$-ray incidence.

A.l spectra are normalized: covered/clean.

to 0,2 in spite of an increase by a factor 4 in the adsorbate due count rate. This decrease can be understood in terms of scattered radiation from the substrate.

Because of the low counting rate, the statistical noise is much bigger in the case of the fluorescence and the Auger yield modes. But as one decreases the concentration of the adsorbate atoms, what determines the surface sensitivity and reliability of a detection scheme is $J_{R}$. For $\mathrm{J}_{\mathrm{R}}<0,01$ one has often observed features related to incomplete normalization of the spectra.

Fluorescence yield submonolayer spectra for $\mathrm{C}_{2} \mathrm{H}_{2}, \mathrm{C}_{2} \mathrm{H}_{4}$ and $\mathrm{C}_{2} \mathrm{H}_{6}$ are shown in Fig. 4. The coverages are estimated by TDS spectroscopy. The statistics do not allow the determination of the position of the o-shape 
resonance. A complete discussion about the orientation of the molecules is given elsewhere /8/. In this case, the sharp $\pi$ resonance of $\mathrm{C}_{2} \mathrm{H}_{2}$ can be used to determine the chemical transformation of that species when the temperature of the substrate is raised. At $\sim 110 \mathrm{~K}$ (fioure 5), the height of the $\pi$ resonance decreases. A check using TDS showed that $\mathrm{C}_{2} \mathrm{H}_{2}$ transforms to $\mathrm{C}_{2} \mathrm{H}_{6}$. This decrease in $\pi$ intensity is easily understood as the $\mathrm{C}_{2} \mathrm{H}_{6}$ molecule presents no $\pi$ bonding.

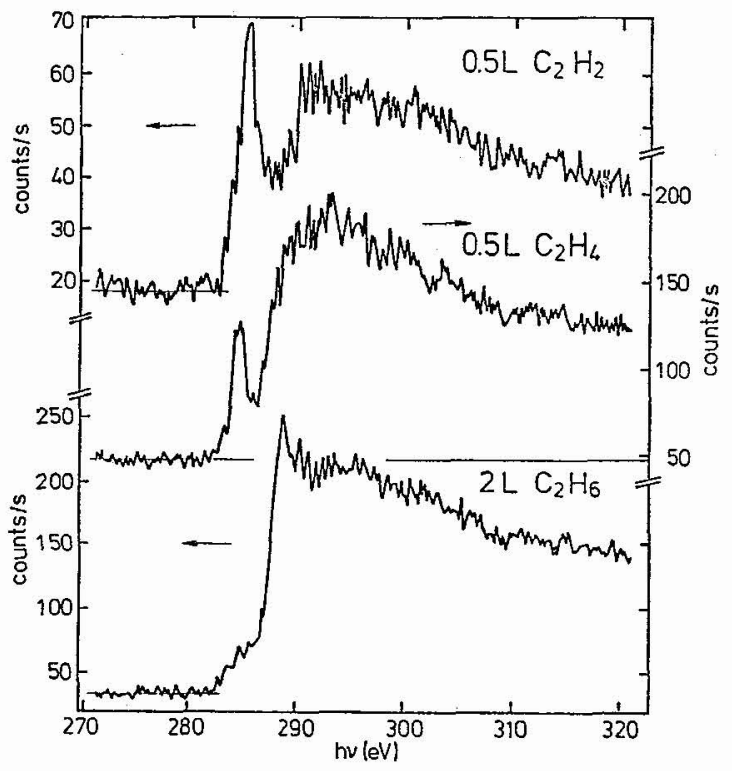

Fig. 4: Submonolayerspectra at normal $\mathrm{x}$-ray incidence for linear hydrocarbon on $\mathrm{Cu}(100)$ at $60 \mathrm{~K}$ using the fluorescence yield mode.

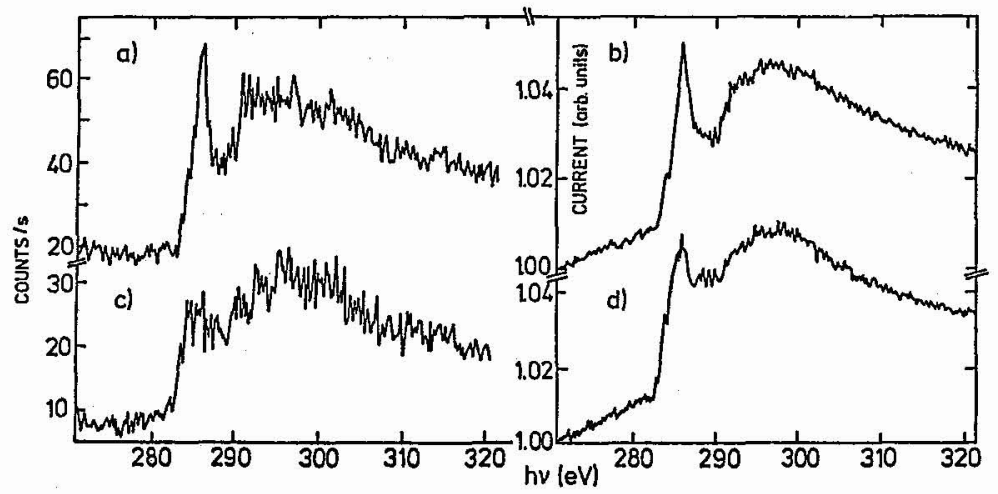

Fig. 5: $\mathrm{C}_{2} \mathrm{H}_{2}$ spectra at submonolayer coverages and normal $\mathrm{X}$-ray incidence? a) $0,5 \mathrm{I}$ fluorescence yield at $60 \mathrm{~K}, \mathrm{~b}) 0,25 \mathrm{I}$ partial electron yield at $60 \mathrm{~K} \mathrm{c}$ ) same as a) wormed up to $\sim 110 \mathrm{~K}$. d) same as b), warmed up to $\sim 130 \mathrm{~K}$. 
These test experiments demonstrate the utility of fluorescence yield detection, even when the absorbate edge is for an element with a low atomic number. With synchrotron facilities of the second generation having one to three orders of magnitude higher photon flux, fluorescence should be the method of choise for surface science investigations.

\section{Acknowledgements}

We acknowledge the help of D.A. Fischer during the early stage of the experiment. The work was supported by BMFT under grant no. O233 BB.

\section{References}

$11 /$ See for example J. Stöhr, Z. Phys. B, 61, 439, (1985)

$12 /$ See for example J. Haase, Appl. Phys. $\bar{A}, 38,181$, (1985)

/3/ J. Stöhr, E.B. Kollin, D.A. Fischer, J.B. Hastings, F. Zaera, and F. Sette, Phys. Rev. Lett. 55, 1468, (1985)

/4/ J. Stöhr, F. Sette and A.I. Johnson, Phys. Rev. Lett 53, 1684, (1984)

/5/ D.A. Fischer, U. Döbler, D. Arvanitis, L. Wenzel, K. Baberschke, and J. Stöhr, Surf. Sci in press

/6/ J. Stöhr, R. Jaeger and S. Brennan, Surf. Sci 117, 503, (1982)

/7/ J. Stöhr, C. Naguera, T. Kendelewitz, Phys. Rev. B, 30, 557, (1984)

$/ 8 / \mathrm{D}$. Arvanitis, U. Döbler, L. Wenzel, K. Baberschke, and J. Stöhr in ECOSS 8, April 1986, Surf Sci to be published. 